\title{
Ca-Al Hydrotalcites as Catalysts for Methanolysis and Ethanolysis of Soybean Oil
}

\author{
E. A. N. Simonetti1,2, G. P. Thim², G. G. Cortez ${ }^{1}$ \\ ${ }^{1}$ Department of Chemistry, Escola de Engenharia de Lorena-Universidade de São Paulo, Lorena, Brazil \\ ${ }^{2}$ Department of Physics, Instituto Tecnológio de Aeronáutica, São José dos Campos, São Paulo, Brazil \\ Email: evelynalvesnunes@yahoo.com.br
}

Received 7 July 2014; revised 13 August 2014; accepted 30 August 2014

Copyright (C) 2014 by authors and Scientific Research Publishing Inc.

This work is licensed under the Creative Commons Attribution International License (CC BY).

http://creativecommons.org/licenses/by/4.0/

(c) (i) Open Access

\section{Abstract}

The use of heterogeneous catalysts in the transesterification reaction of vegetable oils has getting emphasis in recent years, mainly by the alternative of obtaining clean fuel derived from renewable sources. Metal oxide such as $\mathrm{MgO}$ or $\mathrm{CaO}$, supported ones like $\mathrm{Na} / \mathrm{NaOH} / \gamma-\mathrm{Al}_{2} \mathrm{O}_{3} ; \mathrm{KF} / \gamma-\mathrm{Al}_{2} \mathrm{O}_{3}$ and zeolites are often applied in transesterification process. Among them, hydrotalcite has shown potential as catalysts on this reaction due to their physicochemical properties, such as: thermal stability, porosity, specific surface area, memory effect, basicity, acidity and anion exchange capacity. This work studies the catalytic performance of the calcium and aluminum based hydrotalcite in the transesterification reaction of soybean oil in methanol and ethanol. The hydrotalcite samples treated at $450^{\circ} \mathrm{C}$ were impregnated with $\mathrm{KOH}$. The efficiency of impregnated and nonimpregnated samples was compared and the non-impregnated one showed the best performance. This property was attributed to the higher availability of active sites used in the transesterification process.

\section{Keywords}

Biodiesel, Transesterification, Ethanol, Methanol, Hydrotalcites, Soybean Oil

\section{Introduction}

Biodiesel is a mixture of ethyl or methyl esters of fatty acids derived from natural sources (vegetable oil or animal fat). This mixture has basically the same specification of mineral diesel, particularly in terms of viscosity and density. The transesterification reaction is the most widely used route for obtaining biodiesel and it is constituted of a set of organic reactions. In a transesterification reaction the ester group ( $\left.\mathrm{R}^{\prime}-\mathrm{COOR}^{\prime \prime}\right)$ is replaced by an alkoxy radical $(\mathrm{OH})$, which is derived from an alcohol. Equation (1) shows an example of a transesterification 
reaction; where a triglyceride molecule reacts with methanol/ethanol producing methyl/ethyl ester and glycerol. The presence of a catalyst (usually an acid or strong base) significantly accelerates the balance of reaction [1].

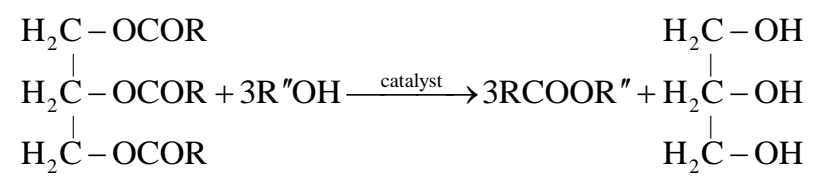

Triglyceride + Alcohol $\stackrel{\text { catalyst }}{\longrightarrow}$ Alkylester + Glycerol

The use of heterogeneous catalysts in the transesterification reaction has been intensely applied due to its reusability and easy separation from the reaction system [2]. Several heterogeneous catalysts have been used, such as: mixed oxide [3], $\mathrm{CaO}$ [4], zirconia [5] and hydrotalcites [6]. Among these, the hydrotalcites (LDHs) are one of the most important due to their large number applications, low cost and wide range of composition [7].

The layered double hydroxides (LDHs) can be represented by the following general formula:

$$
\left[\mathrm{M}_{1-x}^{2+} \mathrm{M}_{x}^{3+}(\mathrm{OH})_{2}\right]^{x+} \mathrm{A}_{x / m}^{m-} \cdot n \mathrm{H}_{2} \mathrm{O}
$$

where:

$$
\begin{aligned}
& \mathrm{M}^{2+}=\text { divalent metal cation; } \\
& \mathrm{M}^{3+}=\text { trivalent metal cation; } \\
& \mathrm{A}^{m-}=\text { anion interspersed with charge } m-; \\
& n=\text { mols. }
\end{aligned}
$$

$$
x=\frac{n \mathrm{M}^{3+}}{\left(n \mathrm{M}^{2+} n \mathrm{M}^{3+}\right)} ; \quad \text { where } 0.20 \leq x \leq 0.33
$$

The ratio of the di and trivalent cations in HDLs $\left(\mathrm{M}^{2+} / \mathrm{M}^{3+}\right)$ can vary from 1 to 8 and $x$ corresponds to a range between 0.20 and 0.33 . This ratio determines the charge density on each layer and has great influence on the material properties such as crystallinity [8]. The thermal processing of HDL promotes the formation of metastable crystalline phases, such as the spinel phase and/or mixed oxides, forming acid and/or basic sites [9]. The transesterification reaction performed by basic catalysis promotes the formation of alkoxides by a nucleophilic attack of oil molecules. However, when acid catalysts are used the transesterification reaction occurs by a protonation step of the carbonyl group of the triglyceride molecule, also via nucleophilic attack [1]. There are four different types of active sites identified in calcined HDL samples: isolated $\mathrm{O}^{2-}$ ions, pairs of $\mathrm{Mg}^{2+} \mathrm{O}^{2-}$ and $\mathrm{OH}^{-}$ groups and acid sites $\mathrm{Al}^{3+}[10]$. The development of catalyst with basic site structures is very important because of: short reaction times, low molar ratio of alcohol/oil and better reaction yields. However, these properties are strictly related to synthesis process and temperature, since they are associated with the pore structure and active sites. Various arrangements of di- and trivalent cations have been used in the synthesis of LDHs and they have been applied in several fields, such as: Hydrotalcite based on Mg-Al as a solid catalyst for the methanolysis of soybean oil, the results showed the activity of the catalysts for the methanolysis reaction was correlated closely with their basicity. MgCoAl-LDH derived heterogeneous catalysts for the ethanol transesterification of canola oil to biodiesel, the results showed higher yields at higher ethanol:oil ratios after 5 hours of reaction. Biodiesel prepared from soybean oil with methanol using $\mathrm{Li}-\mathrm{Al}, \mathrm{Mg}-\mathrm{Al}$ and $\mathrm{Mg}-\mathrm{Fe}$ layered double hydroxides (LDHs) as a catalyst for the transesterification reaction and KF/Ca-Al (LDHs) used as catalyst in the transesterification of palm oil with methanol [11]-[14]. The objective of this study is to evaluate the catalytic performance of hydrotalcite in the transesterification reaction using $\mathrm{Ca}-\mathrm{Al}$ based hydrotalcite obtained by continuous precipitation. The effect of the $\mathrm{KOH}$ impregnation on the catalytic activity on material was also studied.

\section{Materials and Methods}

\subsection{Catalyst Synthesis}

The hydrotalcite precursors were prepared from aqueous solutions containing $\mathrm{Ca}$ (NO3) $2 \cdot 6 \mathrm{H}_{2} \mathrm{O}$ and $\mathrm{Al}\left(\mathrm{NO}_{3}\right)_{3} \cdot 9 \mathrm{H}_{2} \mathrm{O}$. The atomic ratio, $\mathrm{y}=\mathrm{Ca}^{2+} / \mathrm{Al}^{3+}$ was equal to 2 . An aqueous solution of $1.5 \mathrm{~mol} . \mathrm{L}^{-1}$ of $\mathrm{K}_{2} \mathrm{CO}_{3}$ was used as a precipitating agent. These two solutions were maintained at $55^{\circ} \mathrm{C}$ and mixed in a reactor keeping $\mathrm{pH}$ of $10.0 \pm 0.4$ during all process. The precipitate was kept at $40^{\circ} \mathrm{C}$ for 24 hours under slow agitation. Then, it 
was separated by vacuum filtration and washed with deionized water up to neutral $\mathrm{pH}$. The precursor was calcined at $450^{\circ} \mathrm{C}$ and named as $2 \mathrm{Ca}-\mathrm{Al}$ calcined. The impregnation of the 2Ca-Al precursor was carried out in a roto-evaporator, keeping low pressure and $70^{\circ} \mathrm{C}$ until the water is completely eliminated. After impregnation steps, the catalysts were dried at $90^{\circ} \mathrm{C}$ for 24 hours and calcined at $450^{\circ} \mathrm{C}$ for $4 \mathrm{~h}$. A series of catalysts named as $10 \mathrm{~K} / 2 \mathrm{Ca}-\mathrm{Al}$ and $20 \mathrm{~K} / 2 \mathrm{Ca}-\mathrm{Al}$, where $\mathrm{K}$ correspond to $\mathrm{KOH}$ and 10 and 20 represents the weight percentage of $\mathrm{K}$ impregnated in the catalyst.

\subsection{Surface Area and Pore Volume}

Samples were thermally treated at $300^{\circ} \mathrm{C}$ for 3 hours in order to remove chemicals adsorbed The surface area and pore volume were analyzed in an equipment BEL, model Belsorp II, using nitrogen adsorption at $196^{\circ} \mathrm{C}$ and relative pressures $(\mathrm{P} / \mathrm{P0})$ ranging from 0.05 to 0.35 . The pore distribution was determined using the $\mathrm{BJH}$ method from the adsorption/desorption isotherms and the specific area by BET method.

\subsection{X-Ray Diffraction (XRD)}

X-ray diffraction was performed using the powder method in an SEISERT equipment, model 1001, radiation $\mathrm{CuK} \alpha(\lambda=1.54178 \AA)$ and nickel filter. Crystalline phases were identified using JCPDS (Joint Committee of Powder Diffraction Standards) [15].

\subsection{Isopropanol Decomposition Reaction}

The catalytic performance was evaluated through the decomposition of isopropanol, using a fixed bed reactor (quartz), with a continuous flow of reagents at atmospheric pressure. The activation of the catalyst was performed in situ at $200^{\circ} \mathrm{C}$ for $2 \mathrm{~h}$ at oxygen (AGA, 99.9999\%) atmosphere. The reactor was fed with isopropanol (99.7\%, Merck) using a pump Thermo Separation Products, Model Spectra P100, at $0.05 \mathrm{~mL} \cdot \mathrm{min}^{-1}$ of flow, diluted in a mixture of $\mathrm{He}$ and $\mathrm{O}_{2}$ (molar ratio 3/1) at a flow rate of $74 \mathrm{~mL} \cdot \mathrm{min}^{-1}$. The reaction was carried out in the range of $170^{\circ} \mathrm{C}$ to $310^{\circ} \mathrm{C}$, using a catalyst mass of $100 \mathrm{mg}$ and a residence time factor $\left(\mathrm{W} / \mathrm{F}_{\mathrm{A} 0}\right)$ equal to 2.4 g.h/mol $\mathrm{I}_{\text {Isop. }}$ Gases released by the catalyzed reaction were analyzed on line by a chromatograph Varian GC-3350, equipped with a thermal conductivity detector (TCD) and provided with Carbowax $20 \mathrm{M}$ packed column, operating with a heating temperature between $30^{\circ} \mathrm{C}$ and $150^{\circ} \mathrm{C}$. Helium was used as carrier gas in the column.

\subsection{Conversion of Isopropanol ( $\mathrm{X}_{\text {isop }}$ )}

The conversion $\left(X_{A}\right)$, selectivity $\left(S_{p}\right)$ and specific activity (mols of converted products) were calculated using Equations (3)-(5). It was based on the input and output concentration and assuming a differential reactor:

$$
\begin{array}{r}
X_{A}(\%)=\left(\frac{n_{I}}{n_{I o}}\right) 100 \\
S_{p}(\%)=\left(\frac{n_{p}}{n_{I}}\right) \cdot\left(\frac{N_{C P}}{N_{C I}}\right) 100 \\
\text { Specific Activity }=\frac{F_{A o} X_{A} S_{p}}{W_{A} S_{g}}
\end{array}
$$

where:

$n_{I}$ :mols of isopropanol consumed;

$n_{I o}$ : mols of isopropanol fed;

$N_{C P}$ : mols of carbon atoms formed;

$N_{C I}$ : mols of carbon atoms in isopropanol;

$F_{A o}$ : mols of isopropanol fed per minute;

$W_{A}$ : catalyst mass;

$S_{g}$ : catalyst specific area $\left(\mathrm{m}^{2} \cdot \mathrm{g}^{-1}\right)$. 


\subsection{Transesterification with Methanol and Ethanol}

The catalysts were activated in an oven at $200^{\circ} \mathrm{C}$ for $24 \mathrm{~h}$ and the transesterification reactions were conducted in a spherical reactor $(500 \mathrm{~mL})$ equipped with a mechanical stirring. The amount of catalyst used in each experiment was $10 \%$ relative in mass of soybean oil. The experiments were performed in fixed conditions of temperature: $68.5^{\circ} \mathrm{C}$ (methanol) and $78.5^{\circ} \mathrm{C}$ (ethanol) and molar ratio of 1 to 30 (oil/alcohol). After the reaction the catalyst was separated by vacuum filtration. Then, distilled water was added to filtrate and homogenate. The upper phase was separated and washed twice with distilled water. Then, the sample was centrifuged and trace of methanol and ethanol were removed by distillation. The biodiesel was finally dried with anhydrous sodium sulfate and stored at $4^{\circ} \mathrm{C}$ for further analysis.

\subsection{Proton Nuclear Magnetic Resonance ( ${ }^{1} \mathrm{H}$ NMR)}

Aliquots of biodiesel were diluted in deuterated chloroform (CDCl3, Aldrich) and analyzed in a spectrometer model Varian MERCURY $300 \mathrm{MHz}$ operating in the region from 4.4 to $4.0 \mathrm{ppm}$. The absorption signals of chloroform were used as internal reference for the standard scale. The values of chemical shifts are expressed in units (ppm), coupling constants (J) and Hertz (Hz).

\subsection{Methodology for Quantification of Methyl Esters and Ethyl Esters}

The quantification of methyl ester group of the biodiesel was performed by proton nuclear magnetic resonance ( ${ }^{1} \mathrm{H}$ NMR) and based on the technique proposed by Gelbart et al. (1995) [16]. This method uses the ratio between the area related to methylenic protons of the $\alpha$-carbonyl group (-OCOCH $\left.2_{2}^{-}\right)$and the area of hydrogen methoxyl ( $\left.\mathrm{CH}_{3} \mathrm{OCO}-\right)$, according to Equation (6)

$$
C m(\%)=100 \times \frac{2 \times A_{1}}{3 \times A_{2}}
$$

where:

$A_{1}=$ area under hydrogen methoxyl group;

$A_{2}=$ area under methylene protons of $\alpha$-carbonyl;

$\mathrm{Cm}(\%)=$ conversion of oil to methyl esters.

The ethanolysis conversion evaluation was based on the signals present in the region of 4.05 to $4.35 \mathrm{ppm}$ of ${ }^{1} \mathrm{H}$ NMR spectrum. The resonance peak of the etoxyl hydrogen atoms of the ethyl esters is split into a quartet. The area under of the first and fourth peak is $A_{t} / 8$ and that one under the second and third is $3 A_{t} / 8$, where $A_{t}$ is the sum of areas under the four peaks. The fourth component $\left(A c_{4}\right)$ of the quartet of ethyl esters (range 4.07 to $4.08 \mathrm{ppm}$ ) is a single peak that does not suffer overlap from any other peak, so that component was used to calculate the conversion of ethanolysis vegetable oils, according to Equation (7) [17]:

$$
E E(\%)=\left(\frac{8 A_{c 4}}{A_{d d+e e}}\right) 100
$$

where:

$A_{c 4}=$ area of the component fourth peak;

$A_{d d+e e}=$ area of all signals between 4.35 and 4.05 ppm;

$E E(\%)=$ percentage of ethyl esters in vegetable oils.

\section{Results and Discussion}

Figure 1 shows the $\mathrm{X}$-ray diffraction (XRD) profiles of the 2Ca-Al uncalcined, 2Ca-Al calcined at $450^{\circ} \mathrm{C}, 10$ $\mathrm{K} / 2 \mathrm{Ca}-\mathrm{Al}$ calcined at $450^{\circ} \mathrm{C}$ and $20 \mathrm{~K} / 2 \mathrm{Ca}-\mathrm{Al}$ calcined at $450^{\circ} \mathrm{C}$. In the sample 2Ca-Al uncalcined the peaks at $15^{\circ}, 18^{\circ}, 20^{\circ}, 23^{\circ}$ are associated to a layered structure. However, these peaks are centered at much lower values of degree than those reported in the literature for Mg-Al based HDL. This down shift can be associated to the relatively elevated temperature of drying and calcination used in this work, which increased the rate of water and carbon dioxide releasing. This phenomenon damages the solid structure leading to a loss of the lamellar arrangement. High temperatures of synthesis and calcination promote the loss of layered structure. They observed 


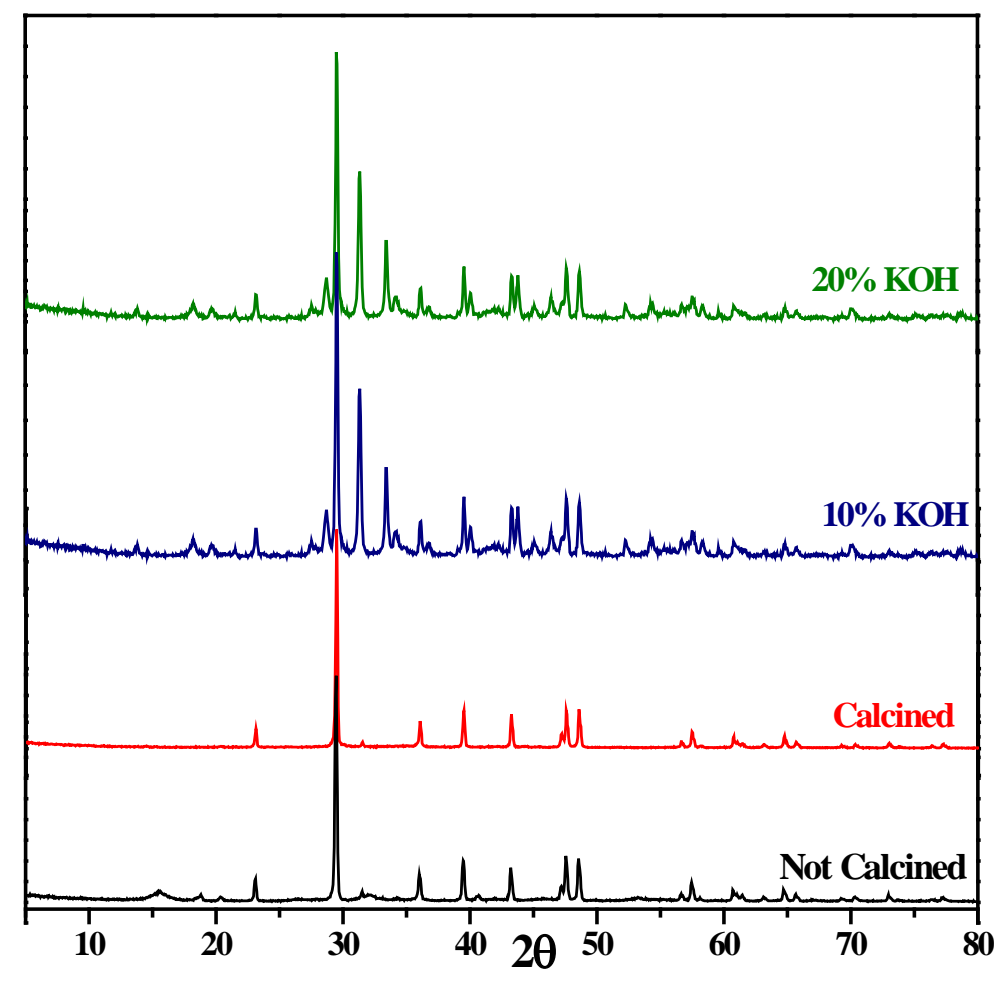

Figure 1. XRD patterns of samples 2Ca-Al uncalcined, 2Ca-Al calcined at $450^{\circ} \mathrm{C}, 10 \mathrm{~K} / 2 \mathrm{Ca}-\mathrm{Al}$ and $20 \mathrm{~K} / 2 \mathrm{Ca}-\mathrm{Al}$.

the presence of basal planes of LDH-Ca/Al only when the samples were prepared at room temperature or calcined at temperature lower than $400^{\circ} \mathrm{C}$. The samples 2Ca-Al uncalcined and 2Ca-Al calcined also presents peaks at $29^{\circ}, 47^{\circ}$ and $48^{\circ}$ (JCPDS 72-1652) related to the formation of $\mathrm{CaCO}_{3}$ crystals (calcite). This formation is a result of $\mathrm{Ca}^{2+}$ agglomeration, which is known by its intense peaks at $2 \theta$ equal to $29^{\circ}, 47^{\circ}$ and $48^{\circ}$. The loss of the layered structure promoted the formation of great amount of $\mathrm{CaCO}_{3}$ and a less abundance of $\mathrm{Al}_{2} \mathrm{O}_{3}$, which can co-exist in the $2 \mathrm{Ca}-\mathrm{Al}$ calcined and uncalcined samples. The formation of oxides like $\mathrm{CaO}, \mathrm{Al}_{2} \mathrm{O}_{3}$ and intercalated carbonates occurs by the calcination of $\mathrm{LDH}-\mathrm{Ca} / \mathrm{Al}$ and the incorporation of $\mathrm{Ca}^{2+}, \mathrm{Al}^{3+}$ and $\mathrm{CO}_{3}^{-}$on the oxide structure is promoted by alkaline conditions. In addition, the preparation method does not ensure the uniform mixing of the $\mathrm{Ca}^{2+}$ and $\mathrm{Al}^{3+}$ ions and $\mathrm{Ca}^{2+}$ cations can agglomerate, promoting the formation of $\mathrm{CaCO}_{3}$ crystals. Therefore, $\mathrm{Ca}^{2+}$ ions could precipitate as calcite, which was characterized by intense peaks in $36^{\circ}, 39^{\circ}$ and $43^{\circ}$. The absence of peaks of $\mathrm{CaO}, \mathrm{Ca}(\mathrm{OH})_{2}$ and $\mathrm{CaAl}_{2} \mathrm{O}_{4}$ in the XRD patterns indicates that these compounds may be present in an amorphous state or highly dispersed on the support, but does not rule out the possibility of crystallite size be less than $4 \mathrm{~nm}^{2}$, which is the lower limit of detection of crystalline structures by the XRD technique [14] [18]-[20].

Figure 1 also shows the XRD patterns of catalyst with different contents of $\mathrm{KOH}$. The addition of KOH promotes the enhancement of the peaks at $29^{\circ}, 36^{\circ}, 39^{\circ}, 43^{\circ}, 47^{\circ}$ and $48^{\circ}$ and the appearance of new peaks at $14^{\circ}$, $18^{\circ}, 31^{\circ}$ and $33^{\circ}$. Comparing with the standard patterns, the first set of peaks can be related to introduction of $\mathrm{KOH}$ on the structure of $\mathrm{CaCO}_{3}$ promoting the increase of these peaks. The other peaks probably belong to potassium oxides. Figure 2 shows the nitrogen adsorption/desorption isotherms measured at $-196^{\circ} \mathrm{C}$ on $2 \mathrm{Ca}-\mathrm{Al}$ calcined, $10 \mathrm{~K} / 2 \mathrm{Ca}-\mathrm{Al}$ and $20 \mathrm{~K} / 2 \mathrm{Ca}-\mathrm{Al}$ catalysts. Table 1 shows the characteristic parameters of the porosity of these catalysts, such as specific surface areas $\left(\mathrm{S}_{\mathrm{BET}}\right)$ and total pore volumes $\left(\mathrm{V}_{\mathrm{p}}\right)$. The isotherms can be classified as type III (IUPAC classification-International Union of Pure and Applied Chemistry). The shape of these isotherms is characteristic of non-porous or macroporous particles which interact very weakly with the adsorbent molecules. This isotherm type is characteristic of systems with adsorption heat virtually nil and related to small gas volumes. This is often observed in the sintered samples with surface area less than $5 \mathrm{~m}^{2} \cdot \mathrm{g}^{-1}$. The hysteresis type is $\mathrm{H} 3$, which does not exhibit any limiting adsorption at high $\mathrm{p} / \mathrm{p}_{0}$ with aggregates of plate-like particles giving rise to slit-shaped pores. The addition of $\mathrm{KOH}$ decreases the intensity of adsorption/desorption curve and 


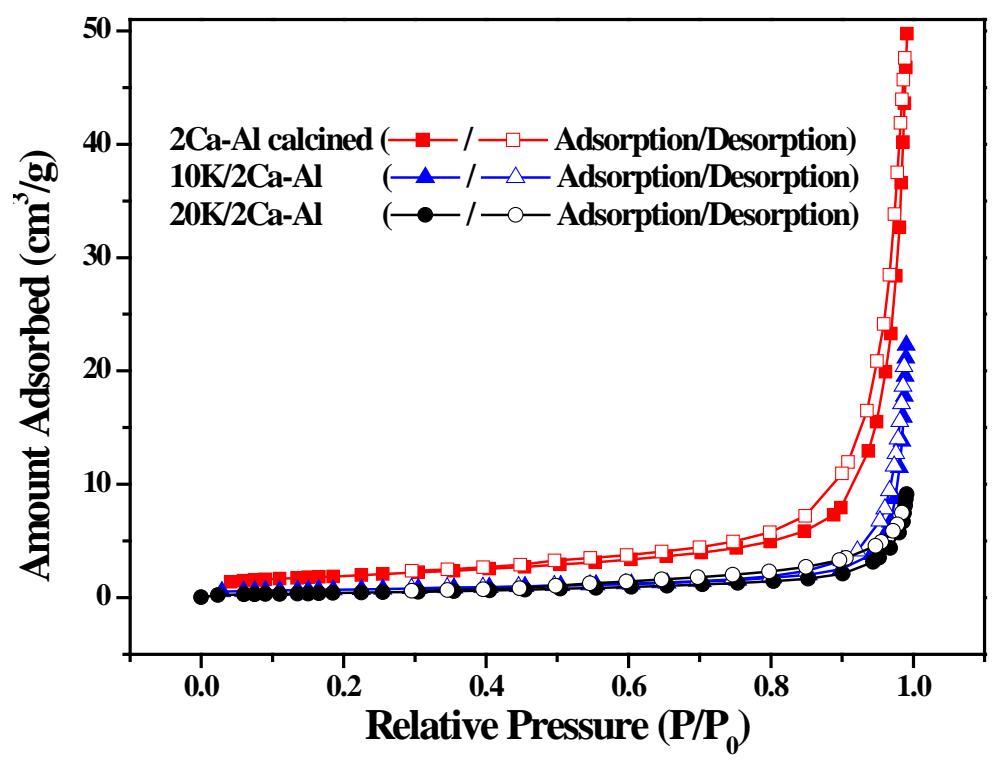

Figure 2. Nitrogen adsorption/desorption isotherms at $-196^{\circ} \mathrm{C}$ of samples 2Ca-Al calcined, $10 \mathrm{~K} / 2 \mathrm{Ca}-\mathrm{Al}$ and $20 \mathrm{~K} / 2 \mathrm{Ca}-\mathrm{Al}$.

Table 1. Values of specific surface area $\left(\mathrm{S}_{\mathrm{BET}}\right)$ and specific pore volume $\left(\mathrm{V}_{\mathrm{p}}\right)$ of the samples 2Ca-Al calcined, $10 \mathrm{~K} / 2 \mathrm{Ca}-\mathrm{Al}$ and $20 \mathrm{~K} / 2 \mathrm{Ca}-\mathrm{Al}$.

\begin{tabular}{ccc}
\hline Catalyst & $\mathrm{S}_{\mathrm{BET}}\left(\mathrm{m}^{2} \cdot \mathrm{g}^{-1}\right)$ & $\mathrm{V}_{\mathrm{p}}\left(\mathrm{cm}^{3} \cdot \mathrm{g}^{-1}\right)$ \\
\hline 2Ca-Al calcined & 6.60 & 0.07 \\
$10 \mathrm{~K} / 2 \mathrm{Ca}-\mathrm{Al}$ & 2.40 & 0.03 \\
$20 \mathrm{~K} / 2 \mathrm{Ca}-\mathrm{Al}$ & 1.70 & 0.01 \\
\hline
\end{tabular}

decreases the values of surface area and specific pore volume as showed in Table 2 . This reduction is due to the incorporation of cations $\mathrm{K}^{+}$in the structure of the precursor $2 \mathrm{Ca}-\mathrm{Al}$ calcined, filling the pores present in the structure [21]-[23].

Figure 3 shows the pore size distribution (estimated by $\mathrm{N} 2$ adsorption) of the $2 \mathrm{Ca}-\mathrm{Al}$ calcined, $10 \mathrm{~K} / 2 \mathrm{Ca}-\mathrm{Al}$ and $20 \mathrm{~K} / 2 \mathrm{Ca}-\mathrm{Al}$ catalysts. It can be note that the porous structure of all samples are basically composed of pore in the mesoporos region $(2 \mathrm{~nm}<\mathrm{w}<50 \mathrm{~nm}$ ) with multimodal distribution indicating heterogeneity in the samples. Presence of one major peak at around $10 \mathrm{~nm}$ for the 2Ca-Al calcined can be observed. The major peaks for the other catalysts were about $2 \mathrm{~nm}$ and $10 \mathrm{~nm}$.

Table 2 shows the results of specific catalytic activity of the catalysts evaluated in isopropanol decomposition reaction at $250^{\circ} \mathrm{C}, 280^{\circ} \mathrm{C}$ and $300^{\circ} \mathrm{C}$. The isopropanol decomposition reaction on the samples promotes the formation of dehydrated products with acid-base sites of different nature and strength. The main products were propylene and diisopropyl ether.

The decomposition reaction of isopropanol promotes the formation of acetone and propylene and diisopropyl ether. Acetone is formed by a dehydrogenation reaction, while propylene and diisopropyl ether are obtained by a dehydration one. Isopropanol decomposition occurs by three different mechanisms: $E_{1}, E_{2}$ and $E_{1 B}$. Propylene is formed by $E_{1}$ mechanism using the strong acid sites of the catalyst. However, depending on acid-base properties of the catalysts the dehydration or dehydration of isopropanol may also happen via $E_{1 B}$ or $E_{2}$ mechanisms. The $\mathrm{E}_{1 \mathrm{~B}}$ mechanism can form propylene and acetone. The formation of propylene by $\mathrm{E}_{1 \mathrm{~B}}$ mechanism requires acid and basic sites with unbalanced forces, namely weak acid sites of Lewis and strong bases of Bronsted. However, the acetone formation occurs on strong base sites provided by the highest density of $\mathrm{CaO}$ pairs of the catalyst samples. The mechanism $E_{2}$ promotes the formation of propylene and diisopropyl ether with acidic sites of Lewis and basic sites with medium or strong forces. However, it was reported the dehydration decomposition reaction of isopropanol is performed by the Bronsted acid groups on the $\mathrm{MgO}$ sites and samples with great 


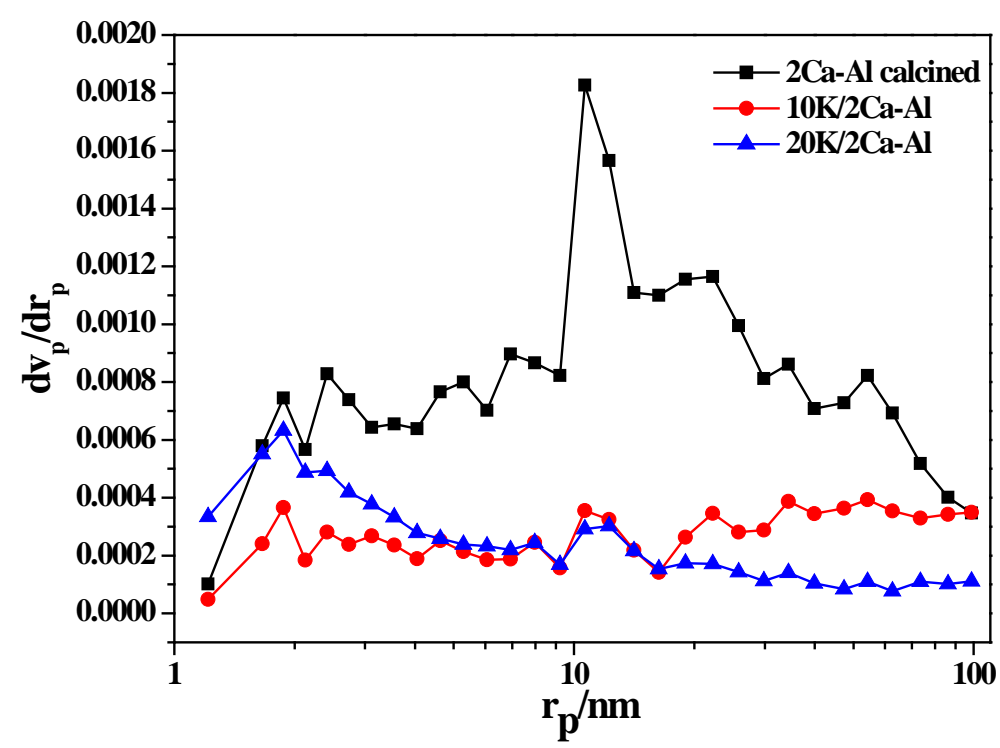

Figure 3. Pore size distribution of the $2 \mathrm{Ca}-\mathrm{Al}$ calcined, $10 \mathrm{~K} / 2 \mathrm{Ca}-\mathrm{Al}$ and 20 $\mathrm{K} / 2 \mathrm{Ca}-\mathrm{Al}$ catalysts.

Table 2. Specific catalytic activity of samples 2Ca-Al calcined, $10 \mathrm{~K} / 2 \mathrm{Ca}-\mathrm{Al}$ and $20 \mathrm{~K} / 2 \mathrm{Ca}-\mathrm{Al}$.

\begin{tabular}{ccccccc}
\hline & \multicolumn{5}{c}{ Specific Catalytic Activity $\left(10^{-4} \mathrm{~mol} \cdot \mathrm{m}^{-2} \cdot \mathrm{min}^{-1}\right)$} \\
\cline { 2 - 7 } Catalyst & \multicolumn{7}{c}{ Propylene } & Diisopropyl Ether \\
\cline { 2 - 7 } & $250^{\circ} \mathrm{C}$ & $280^{\circ} \mathrm{C}$ & $300^{\circ} \mathrm{C}$ & $250^{\circ} \mathrm{C}$ & $280^{\circ} \mathrm{C}$ & $300^{\circ} \mathrm{C}$ \\
\hline 2 Ca-Al Calcined & 0.110 & 0.440 & 1.400 & 0.002 & 0.140 & 0.660 \\
$10 \mathrm{~K} / 2 \mathrm{Ca}-\mathrm{Al}$ & 0.770 & 2.110 & 4.200 & 0.010 & 0.680 & 1.890 \\
$20 \mathrm{~K} / 2 \mathrm{Ca}-\mathrm{Al}$ & 0.420 & 2.010 & 6.130 & 0.020 & 1.000 & 2.720 \\
\hline
\end{tabular}

amount of aluminum ions are more propylene formation selective due to the high density of $\mathrm{Al}^{3+} \mathrm{O}^{2-}$ groups on the surface [24]-[26]. The formation of propylene can occur via two mechanisms: $E_{1 c}$ and $E_{2 c}$. The mechanism $\mathrm{E}_{1 \mathrm{c}}$ is related to the adsorption of alcohol molecule on catalyst surface and the O-H bond rupture on the acidstrong base pair site. The $\mathrm{E}_{1 \mathrm{c}}$ mechanism leads to attraction of the most acidic proton in the ethoxy intermediate on the basic site, with formation of carbanion by a C-H bond rupture, forming olefins. Propylene can also be formed by a single-step mechanism $E_{2 c}$ which involves acid and base sites of balanced strength, without any formation of ionic intermediate. The acid site that participates of mechanism $E_{1 c}$ should be stronger than which one participating in the mechanism $\mathrm{E}_{\mathrm{c} 2}$. Diisopropyl ether is formed by mechanism $\mathrm{E}_{\mathrm{c} 3}$ and it is a second-order reaction that involves the adsorption of two alcohol molecules onto adjacent two different types of site. One molecule adsorbs on a Lewis acid site through the oxygen of the $\mathrm{OH}$ group, making the $\mathrm{C}^{\alpha}$ atom slightly positive. The other alcohol molecule adsorbs on a basic site via H-bond, increasing the nucleophilicity of the oxygen of the $\mathrm{OH}$ group. The adsorbed second alcohol molecule forms an alkoxide ion, performing a nucleophilic displacement on the $\mathrm{C}^{\alpha}$ atom of the alcohol molecule to form the diisopropyl ether molecule. Table 2 shows isopropanol decomposition performed by samples $2 \mathrm{Ca}-\mathrm{Al}$ calcined, $10 \mathrm{~K} / 2 \mathrm{Ca}-\mathrm{Al}$ and $20 \mathrm{~K} / 2 \mathrm{Ca}-\mathrm{Al}$ were dependent on temperature. The concentration of both propylene and diisopropyl ether increased when temperature also increased. Table 2 shows $20 \mathrm{~K} / 2 \mathrm{Ca}$-Al has higher specific catalytic activity to propylene and diisopropyl ether at $300^{\circ} \mathrm{C}$ than $10 \mathrm{~K} / 2 \mathrm{Ca}-\mathrm{Al}$ followed by $2 \mathrm{Ca}-\mathrm{Al}$ calcined sample. Therefore, one can conclude all samples are composed by Lewis or Bronsted acid sites and sample $20 \mathrm{~K} / 2 \mathrm{Ca}$-Al has more acidic characteristic than the other ones. The increase of specific catalytic activity of the $10 \mathrm{KCa}-\mathrm{Al}$ and $20 \mathrm{~K} / 2 \mathrm{Ca}-\mathrm{Al}$ compared to 2Ca-Al calcined is related to the increase of electron density on the samples due to adding of $\mathrm{KOH}$ [10]. The evolution of methanolysis reaction was evaluated by the decrease of the signal intensity of triglycerides molecules with the reac- 
tion time. The ${ }^{1} \mathrm{H}$ NMR spectra give the relative number of hydrogen atom of each methylene group based on the integration between 4.05 and $4.40 \mathrm{ppm}$. Figure 4 shows that at the end of reaction these signals disappeared, indicating a high conversion of triglycerides to methyl esters. The appearance of the characteristic signal of methoxyl hydrogens in the region between 3.75 and 3.5 ppm can also be observed.

Table 3 shows values of the integrated areas of the singlet $\left(A_{1}\right)$ and triplet $\left(A_{2}\right)$ peaks. The yield of methyl esters was determined from Equation 5. The singlet signal $\left(\mathrm{A}_{1}\right)$ represents the methoxyl hydrogen and the triplet $\left(\mathrm{A}_{2}\right)$ the $\alpha$-carbonyl hydrogen. These areas shows the calcined 2Ca-Al calcined sample showed the best performance for the methanolysis reaction of soybean oil, followed by samples $10 \mathrm{~K} / 2 \mathrm{Ca}-\mathrm{Al}$ and $20 \mathrm{~K} / 2 \mathrm{Ca}-\mathrm{Al}$. Although the samples $10 \mathrm{~K} / 2 \mathrm{Ca}-\mathrm{Al}$ and $20 \mathrm{~K} / 2 \mathrm{Ca}$-Al showed higher catalytic activity than 2Ca-Al calcined in the isopropanol decomposition reaction, the addition of $\mathrm{K}^{+}$ions on the precursor structure resulted in a decrease of the conversion percentage of ethyl esters. It can be argued that despite the impregnated compounds have higher specific catalytic activity, the lower specific area of these compounds compared to the precursor 2Ca-Al calcined did not contributed to a higher conversion in biodiesel. Besides that, the elevated density of these active sites was not effective in triglyceride breaking down. The active site responsible to this mechanism may be associated to the calcium or aluminum contents on the samples [16].

The method proposed by Garcia (2006) [17] was used to evaluate the conversion triglycerides of ethyl esters. This technique is based on the signals present in the region of 4.05 to $4.35 \mathrm{ppm}$ of ${ }^{1} \mathrm{H}$ NMR spectrum. This region represents the methylene hydrogens of triglycerides molecules of soybean. After transesterification reaction the signals of etoxyl hydrogen of ester molecules takes place. The ${ }^{1} \mathrm{H}$-NMR spectra (Figure 5) of the product obtained from the samples $10 \mathrm{~K} / 2 \mathrm{Ca}-\mathrm{Al}$ and $20 \mathrm{~K} / 2 \mathrm{Ca}-\mathrm{Al}$ show an overlap between the signs of the etoxyl hydrogen of ester molecules with the methylene hydrogen of triglyceride molecules in the region of 4.05 to 4.4 $\mathrm{ppm}$. Therefore, this overlapping is an indication of partial conversion of the triglyceride to ester substances. Nevertheless, the spectrum of the reaction catalyzed by $2 \mathrm{Ca}-\mathrm{Al}$ calcined showed no overlap between these

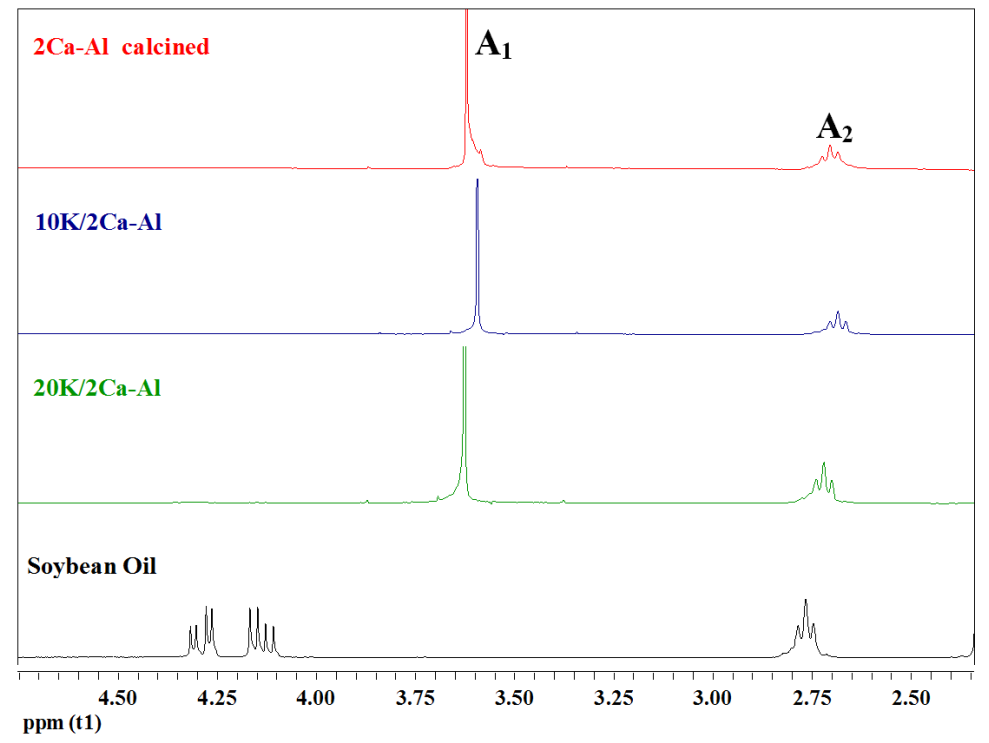

Figure 4. ${ }^{1} \mathrm{H}$ NMR spectra of soybean oil and methyl ester catalyzed by 20 $\mathrm{K} / 2 \mathrm{Ca}-\mathrm{Al}, 10 \mathrm{~K} / 2 \mathrm{Ca}-\mathrm{Al}$ and $2 \mathrm{Ca}-\mathrm{Al}$ calcined in the region between $4.5-2.5$ ppm.

Table 3. Integration peaks and the conversion percentage determined by ${ }^{1} \mathrm{H}$ NMR (methanol).

\begin{tabular}{cccc}
\hline Sample & $\mathrm{S}_{\mathrm{BET}}\left(\mathrm{m}^{2} \cdot \mathrm{g}^{-1}\right)$ & $\mathrm{V}_{\mathrm{p}}\left(\mathrm{cm}^{3} \cdot \mathrm{g}^{-1}\right)$ & Conversion $(\%)$ \\
\hline 2Ca-Al calcined & 1.03 & 0.68 & 100 \\
$10 \mathrm{~K} / 2 \mathrm{Ca}-\mathrm{Al}$ & 1.00 & 0.70 & 95 \\
$20 \mathrm{~K} / 2 \mathrm{Ca}-\mathrm{Al}$ & 1.29 & 0.96 & 90 \\
\hline
\end{tabular}


signals indicating an elevated conversion to ethyl ester. Table 4 shows the integration values of signals between 4.06 and $4.35 \mathrm{ppm}$. One can observe that the precursor 2Ca-Al calcined showed the most elevated conversion to ethyl esters, followed by $10 \mathrm{~K} / 2 \mathrm{Ca}-\mathrm{Al}$ and $20 \mathrm{~K} / 2 \mathrm{Ca}-\mathrm{Al}$. The difference between the yields of reaction of 2Ca-Al calcined and the impregnated catalysts was higher when compared to methanolysis. These results are associated with the greater reactivity of methanol when compared to ethanol.

According to the Table 3 and Table 4 the methanolysis of soybean oils showed a better performance when compared to ethanolysis. The reactions with methanol reached a conversion of $100 \%$ with calcined 2Ca-Al catalyst while the highest conversion with ethanol was $94 \%$. The alcohol substances that can be used in the transesterification process include methanol, ethanol, propanol, butanol and amyl alcohol. Among these, methanol and ethanol are the most common. Methanol is especially used because of its lower cost and its physical and chemical advantages. Methanol can react with triglycerides quickly and the alkali catalyst is easily dissolved in it. Moreover, ethanol can form an azeotrope with water that requires higher reaction times and molar ratio (oil/alcohol) [27].

\section{Conclusion}

The calcined hydrotalcites were considered effective as catalysts of soybean oil both with ethanol as methanol. When the reaction was carried out with the 2Ca-Al catalyst the conversion of soybean oil was $94 \%$ with ethanol and $100 \%$ with methanol. Although, when the impregnated catalysts were used the yields were much lower to the ethanolysis when compared with the methanolysis. The conversion for ethanolysis reached a maximum of 58\% while the methanolysis kept the conversion between $90 \%$ - 95\%. The catalytic performance of the catalysts is related to the acid properties determined in isopropanol decomposition reaction. The higher acid activity on the impregnated catalysts was unfavorable to the transesterification reaction. This was more pronounced on ethanolysis. Besides the higher acid activity of these catalysts the low conversion is also associated to the lower reactivity of ethanol and the formation of azeotropic system which is hard to disassociate and the lower surface area

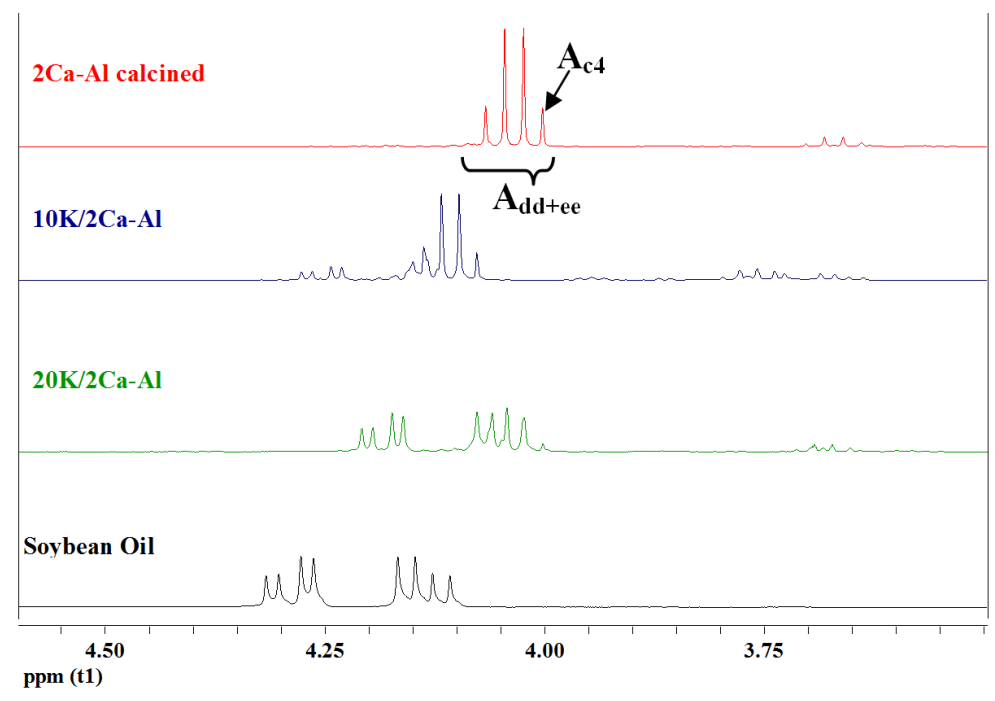

Figure 5. ${ }^{1} \mathrm{H}$ NMR spectra of soybean oil and ethyl ester catalyzed by 20 $\mathrm{K} / 2 \mathrm{Ca}-\mathrm{Al}, 10 \mathrm{~K} / 2 \mathrm{Ca}-\mathrm{Al}$ and $2 \mathrm{Ca}-\mathrm{Al}$ calcined in the region between 4.5 - 3.75 ppm.

Table 4. Integration peaks and the conversion percentage determined by ${ }^{1} \mathrm{H}$ NMR (ethanol).

\begin{tabular}{cccc}
\hline Sample & $\mathrm{S}_{\mathrm{BET}}\left(\mathrm{m}^{2} \cdot \mathrm{g}^{-1}\right)$ & $\mathrm{V}_{\mathrm{p}}\left(\mathrm{cm}^{3} \cdot \mathrm{g}^{-1}\right)$ & Conversion (\%) \\
\hline 2Ca-Al calcined & 1.06 & 7.58 & 94 \\
$10 \mathrm{~K} / 2 \mathrm{Ca}-\mathrm{Al}$ & 1.00 & 12.90 & 58 \\
$20 \mathrm{~K} / 2 \mathrm{Ca}-\mathrm{Al}$ & 1.00 & 40.35 & 20 \\
\hline
\end{tabular}


of the impregnated compounds. The catalysts were also characterized with XRD, BET and isopropanol decomposition reaction. The XRD analysis showed the presence of calcite $\left(\mathrm{CaCO}_{3}\right)$ observed in the $\mathrm{Ca}-\mathrm{Al}=2$ catalyst, resulting in low surface area and pore volume as characterized on BET. The isopropanol decomposition reaction promotes the formation of propylene and diisopropyl ether by $\mathrm{Al}^{3+} \mathrm{O}^{2-}$ sites present on the catalysts surface which probably is the responsible for their catalytic activities. Besides high conversion obtained, the use of this heterogeneous catalysts has the advantage of its easy separation from the reaction mixture which can be of commercial interest.

\section{References}

[1] Schuchardt, U., Sercheli, R. and Vargas, R.M. (1998) Transesterification of Vegetable Oils: A Review. Journal of the Brazilian Chemical Society, 9, 199-210. http://dx.doi.org/10.1590/S0103-50531998000300002

[2] Lam, M.K., Lee, K.T. and Mohamed, A.R. (2010) Homogeneous, Heterogeneous and Enzymatic Catalysis for Transesterification of High Free Fatty Acid Oil (Waste Cooking Oil) to Biodiesel: A Review. Biotechnology Advances, 28, 500-518. http://dx.doi.org/10.1016/j.biotechadv.2010.03.002

[3] Ngamcharussrivichai, C., Totarat, P. and Bunyakiat, K. (2008) Ca and Zn Mixed Oxide as a Heterogeneous Base Catalyst for Transesterification of Palm Kernel Oil. Applied Catalysis A: General, 341, 77-85. http://dx.doi.org/10.1016/j.apcata.2008.02.020

[4] Bai, H.-X., Shen, X.-Z., Liu, X.-H. and Liu, S.-Y. (2009) Synthesis of Porous CaO Microsphere and Its Application in Catalyzing Transesterification Reaction for Biodiesel. Transactions of Nonferrous Metals Society of China, 19, s674s677. http://dx.doi.org/10.1016/S1003-6326(10)60130-6

[5] Zabeti, M., Daud, W.M.A.W. and Aroua, M.K. (2009) Activity of Solid Catalysts for Biodiesel Production: A Review. Fuel Processing Technology, 90, 770-777. http://dx.doi.org/10.1016/j.fuproc.2009.03.010

[6] Prescott, H.A., Li, Z., Kemnitz, E., Trunschke, A., Deutsch, J., Lieske, H. and Auroux, A. (2005) Application of Calcined Mg-Al Hydrotalcites for Michael Additions: An Investigation of Catalytic Activity and Acid-Base Properties. Journal of Catalysis, 234, 119-130. http://dx.doi.org/10.1016/j.jcat.2005.06.004

[7] Rives, V. (2002) Characterisation of Layered Double Hydroxides and Their Decomposition Products. Materials Chemistry and Physics, 75, 19-25. http://dx.doi.org/10.1016/S0254-0584(02)00024-X

[8] Crepaldi, E.L. and Valim, J.B. (1998) Hidróxidos Duplos Lamelares: Síntese, Estrutura, Propriedades e Aplicações. Química Nova, 21, 300-311. http://dx.doi.org/10.1590/S0100-40421998000300011

[9] Vaccari, A. (1998) Preparation and Catalytic Properties of Cationic and Anionic Clays. Catalysis Today, 41, 53-71. http://dx.doi.org/10.1016/S0920-5861(98)00038-8

[10] Di Cosimo, J.I., Diez, V.K., Xu, M., Iglesia, E. and Apesteguia, C.R. (1998) Structure and Surface and Catalytic Properties of Mg-Al Basic Oxides. Journal of Catalysis, 178, 499-510. http://dx.doi.org/10.1006/jcat.1998.2161

[11] Xie, W., Peng, H. and Chen, L. (2006) Calcined Mg-Al Hydrotalcites as Solid Base Catalysts for Methanolysis of Soybean Oil. Journal of Molecular Catalysis A: Chemical, 246, 24-32. http://dx.doi.org/10.1016/j.molcata.2005.10.008

[12] Li, E., Xu, Z.P. and Rudolph, V. (2009) MgCoAl-LDH Derived Heterogeneous Catalysts for the Ethanol Transesterification of Canola Oil to Biodiesel. Applied Catalysis B: Environmental, 88, 42-49. http://dx.doi.org/10.1016/j.apcatb.2008.09.022

[13] Shumaker, J.L., Crofcheck, C., Tackett, S.A., Santillan-Jimenez, E., Morgan, T., Ji, Y., Crocker, M. and Toops, T.J. (2008) Biodiesel Synthesis Using Calcined Layered Double Hydroxide Catalysts. Applied Catalysis B: Environmental, 82, 120-130. http://dx.doi.org/10.1016/j.apcatb.2008.01.010

[14] Gao, L., Teng, G., Xiao, G. and Wei, R. (2010) Biodiesel from Palm Oil via Loading KF/Ca-Al Hydrotalcite Catalyst. Biomass and Bioenergy, 34, 1283-1288. http://dx.doi.org/10.1016/j.biombioe.2010.03.023

[15] Joint Committee on Power Diffraction Standards (1983) Powder Diffraction File Published by the International Center of Diffraction Data. 2nd Edition, Swarthmore.

[16] Gelbard, G., Brès, O., Vargas, RM., Vielfaure, F. and Schuchardt, U.F.H. (1995) ${ }^{1}$ H Nuclear Magnetic Resonance Determination of the Yield of the Transesterification of Rapeseed Oil with Methanol. Journal of the American Oil Chemists' Society, 72, 1239-1241. http://dx.doi.org/10.1007/BF02540998

[17] Garcia, C.M. (2006) Transeterification of Vegetable Oils. Msc. Thesis, Universidade Estadual de Campinas, Campinas.

[18] Frost, R.L., Palmer, S.J. and Spratt, H.J. (2009) Hydrotalcites and Their Role in Coordination of Anions in Bayer Liquors: Anion Binding in Layered Double Hydroxides. Journal of Thermal Analysis and Calorimetry, 95, 123-129.

[19] Yu, C., Wang, C., Hsu, M. and Chyou, Y. (2011) Development of a Novel Ca/Al Carbonates for Medium-High Temperature $\mathrm{CO}_{2}$ Capture. Energy Procedia, 4, 787-794. http://dx.doi.org/10.1016/j.egypro.2011.01.120 
[20] Chary, K.V.R., Kishan, G., Kumar, C.P., Sagar, G.V. and Niemantsverdriet, J.W. (2003) Characterization and Reactivity of Vanadium Oxide Catalysts Supported on Niobia. Applied Catalysis A: General, 245, 303-316. http://dx.doi.org/10.1016/S0926-860X(02)00654-3

[21] Kaneko, K. (1994) Determination of Pore Size and Pore Size Distribution: 1. Adsorbents and Catalysts. Journal of Membrane Science, 96, 59-89. http://dx.doi.org/10.1016/0376-7388(94)00126-X

[22] Santilli, C.V. and Pulcinelli, S.H. (1993) Analise da Textura de Materiais Cerâmicos a Partir das Isotermas de Adsorção de Gases. Cerâmica, 39, 11-16.

[23] Sing, S.W. (1982) Reporting Physisorption Data for Gas/Solid System. Pure and Applied Chemistry, 54, $2201-2218$.

[24] Gervasini, A., Fenyvesi, J. and Auroux, A.A. (1997) Study of the Acidic Character of Modified Metal Oxide Surfaces Using the Test of Isopropanol Decomposition. Catalysis Letters, 43, 219-228. http://dx.doi.org/10.1023/A:1018979731407

[25] Díez, V.K., Apesteguía, C.R. and Di Cosimo, J.I. (2003) Effect of the Chemical Composition on the Catalytic Performance of $\mathrm{Mg}_{y} \mathrm{AlO}_{x}$ Catalysts for Alcohol Elimination Reactions. Journal of Catalysis, 215, 220-233.

[26] Aramendia, M.A., Borau, V., Jimenez, C., Marinas, J.M., Porras, A. and Urbano, F.J. (1996) Magnesium Oxides as Basic Catalysts for Organic Processes: Study of the Dehydrogenation-Dehydration of 2-Propanol. Journal of Catalysis, 161, 829-838. http://dx.doi.org/10.1006/jcat.1996.0246

[27] Leung, D.Y.C., Wu, X. and Leung, M.K.H. (2010) A Review on Biodiesel Production Using Catalyzed Transesterification. Applied Energy, 87, 1083-1095. http://dx.doi.org/10.1016/j.apenergy.2009.10.006 
Scientific Research Publishing (SCIRP) is one of the largest Open Access journal publishers. It is currently publishing more than 200 open access, online, peer-reviewed journals covering a wide range of academic disciplines. SCIRP serves the worldwide academic communities and contributes to the progress and application of science with its publication.

Other selected journals from SCIRP are listed as below. Submit your manuscript to us via either submit@scirp.org or Online Submission Portal.
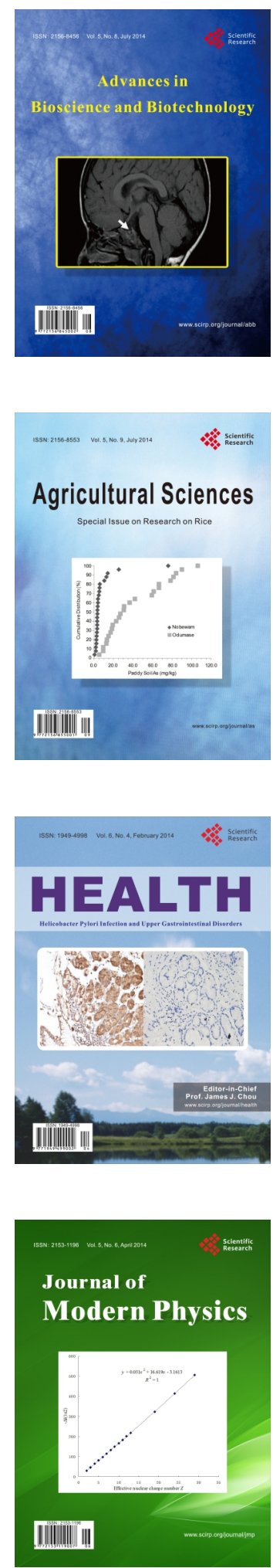
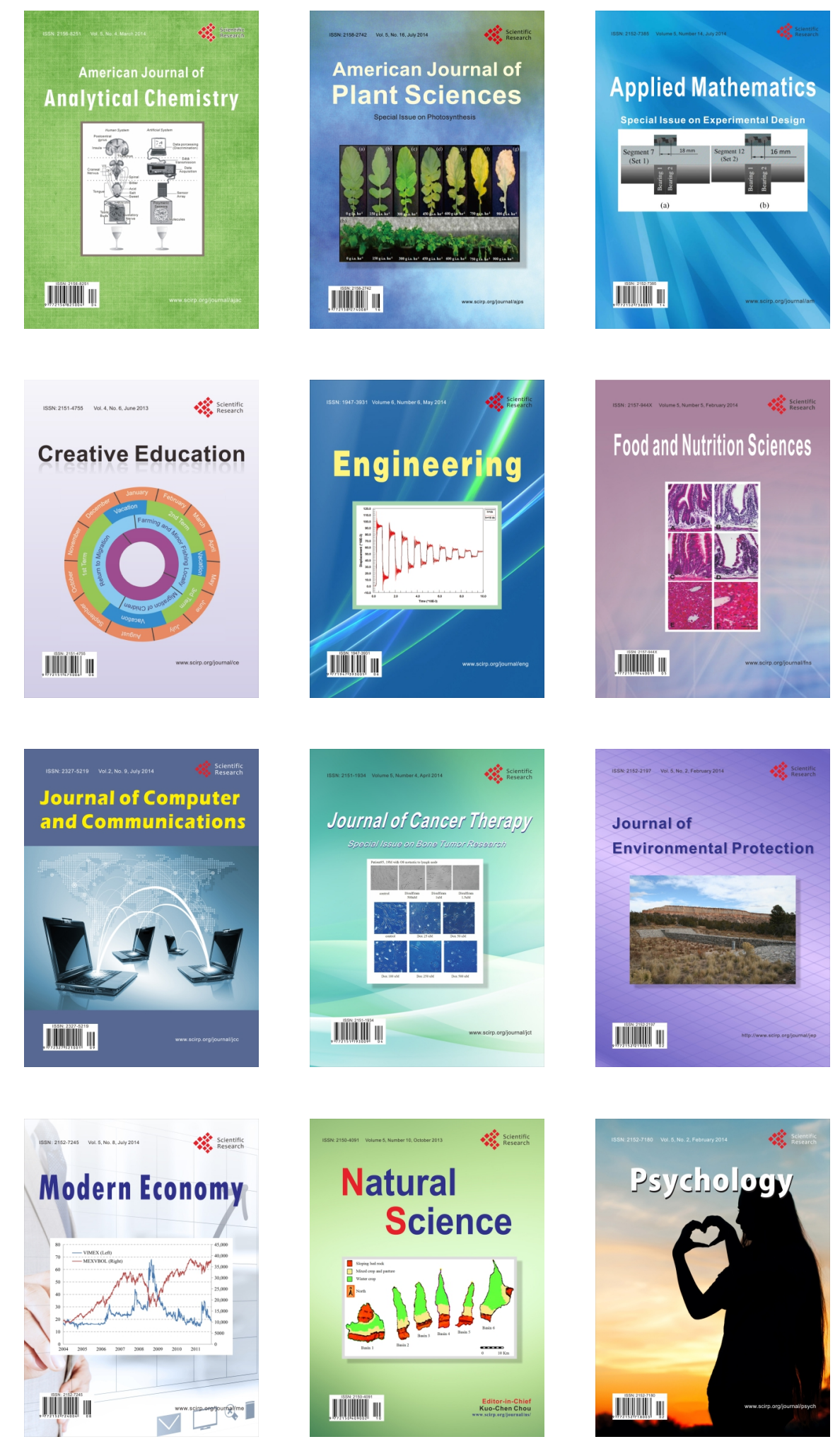